Article

\title{
One-Step Preparative Separation of Phytosterols from Edible Brown Seaweed Sargassum horneri by High-Speed Countercurrent Chromatography
}

\author{
Menglu Xia ${ }^{1}$, Chunping Liu ${ }^{1}$, Lei Gao ${ }^{2}$ and Yanbin Lu ${ }^{1, *(D)}$ \\ 1 Key Laboratory of Aquatic Products Processing of Zhejiang Province, Institute of Seafood, Zhejiang \\ Gongshang University, Hangzhou 310035, China; xm1429821@163.com (M.X.); lcpzjgsu@163.com (C.L.) \\ 2 Hangzhou Nafen BioChem Corporation, Hangzhou 310008, China; gl@zju.edu.cn \\ * Correspondence: luyanbin@zjgsu.edu.cn; Tel.: +86-571-87103135
}

Received: 15 November 2019; Accepted: 5 December 2019; Published: 9 December 2019

check for updates

\begin{abstract}
Sargassum horneri, a sargassaceae brown alga, is one of the main species in the subtidal seaweeds flora extensively distributed in the Yellow and East China Sea. It has been proven that the phytosterols are an important class of bioactive substances in S. horneri. In this work, a counter-current chromatography approach is proposed for preparative separation of phytol and two analogue sterols from a crude extract of $S$. horneri. A two-phase solvent system composed of $n$-hexane-acetonitrile-methanol $(5: 5: 6, v / v)$ was selected and optimized. The effects of rotary speed and flow rate on the retention of the stationary phase were carefully studied. Under the optimum conditions, phytol and two analogue sterols, fucosterol and saringosterol, were baseline separated, producing $19.8 \mathrm{mg}$ phytol, $23.7 \mathrm{mg}$ fucosterol, and $3.1 \mathrm{mg}$ saringosterol from $300 \mathrm{mg}$ of crude $S$. horneri extract in one-step separation. The purities of three target compounds were all above $85 \%$. The structures of phytol and two sterols were identified by nuclear magnetic resonance spectroscopy.
\end{abstract}

Keywords: Sargassum horneri; saringosterol; fucosterol; phytol; high-speed counter-current chromatography; preparative separation

\section{Introduction}

Sargassum horneri, a type of brown algae, is widely distributed in China, Korea, and Japan [1,2]. It is suitable for growing in the sea area which has a strong combination of high water transparency and abundant nutrient salt. S. horneri has been widely used as an edible alga and has various health benefits, such as protective role on bacteria, anti-proliferative effects on cancer cells, anti-inflammatory and antioxidant activity [3-5]. Due to the high content of polysaccharides, there are many studies on polysaccharides, and many achievements have been accomplished [6-8]. While, as another abundant compounds family present in S. horneri, the development of sterol-related health care products is relatively slow. In fact, studies have shown that phytosterols have a wide range of biological activities and have important properties such as antibacterial, antiviral, antioxidant, and so on [9-14]. Recently, fucosterol and saringosterol (see Figure 1) were evaluated for their effects on LXR-mediated transactivation and target gene expression in six cell lines. The exciting result was that 24(S)-saringosterol acts as a novel selective LXR $\beta$ agonist. This study also demonstrated that phytosterols in Sargassum family contributed to the well-known antiatherosclerotic function [9]. However, due to the similar chemical structure and low polarity, traditional purification procedures always suffer from tedious, time-consuming sample pretreatment, re-chromatographic steps, and low yields. 

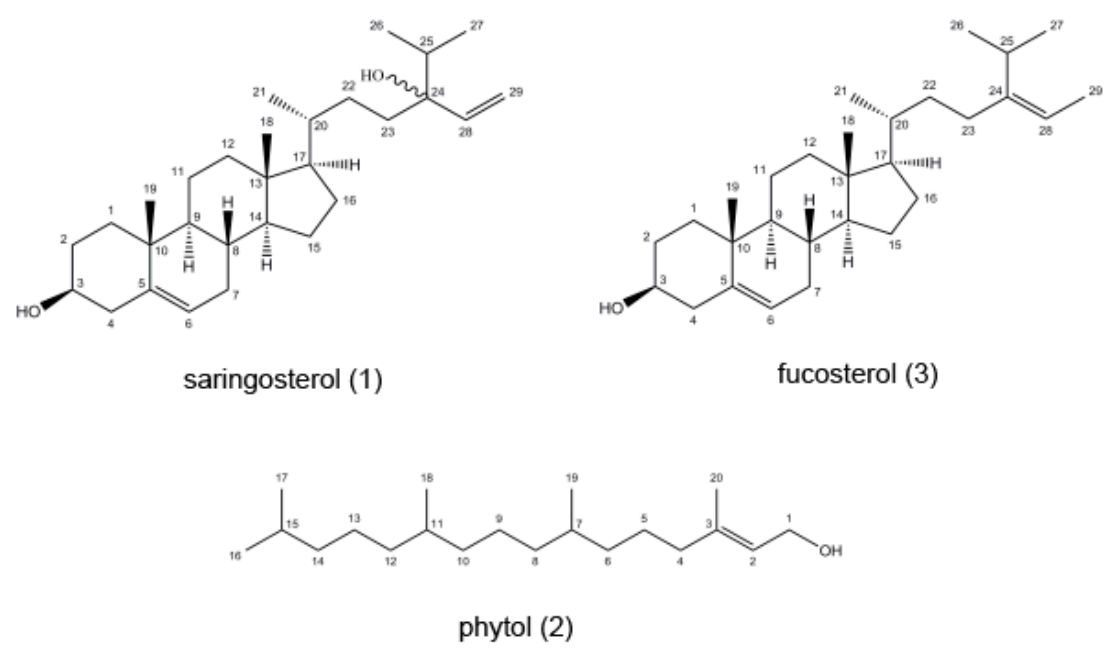

Figure 1. Chemical structures of target compounds separated from S. horneri.

High-speed countercurrent chromatography (HSCCC) is a continuous liquid-liquid distribution chromatographic technique that does not have a solid matrix and relies solely on centrifugal force and its own gravity to retain the stationary phase [15]. This technology achieves the purpose of efficient separation with a two-phase solvent system. Comparing with the traditional liquid-solid chromatography techniques, it benefits from great advantages: eliminating the complications derived from the solid support matrix, such as irreversible adsorptive sample loss and deactivation, tailing of solute peaks, and contamination. CCC has many unique merits, such as higher material recovery and product purity, shorter separation time, a larger scale of sample-loading and a wider range of feasible two-phase solvent systems [16,17]. Therefore, CCC has been successfully applied for the isolation of various bioactive compounds from natural origins [18-22].

The purpose of this study, therefore, is to develop an efficient CCC method to preparative isolation of phytosterols from the crude extract of S. horneri. For this purpose, a two-phase solvent system composed of $n$-hexane-acetonitrile-methanol $(5: 5: 6, v / v)$ was selected and optimized. The effects of rotary speed and flow rate on the retention of the stationary phase were carefully studied. Under the optimum conditions, phytol and two analogue sterols, fucosterol and saringosterol (see Figure 1), were baseline separated from $300 \mathrm{mg}$ of the crude $S$. horneri extract in a one-step separation. The chemical structures of target compounds were identified by nuclear magnetic resonance spectroscopy.

\section{Results and Discussion}

\subsection{HPLC Analysis of the Crude Extract}

In the present work, the crude $S$. horneri extract was obtained by a heat reflux and saponification process. Saponification efficiently removes chlorophylls and lipids, which might result in interference in the spectrophotometric assay of phytosterols [21]. The obtained crude sample was stored in a refrigerator $\left(-20^{\circ} \mathrm{C}\right)$ for the subsequent $\mathrm{CCC}$ separations.

Subsequently, a suitable HPLC method for analysis of the crude sample and peak fractions of HSCCC was optimized. In order to select an appropriate elution system for HPLC analysis of the crude S. horneri extract, different kinds of solvent systems were employed. The results revealed that when methanol and acetonitrile $(3: 7, v / v)$ were used in the isocratic elution mode and the flow rate was $0.8 \mathrm{~mL}$ $\mathrm{min}^{-1}$, the target compounds could be well separated from other components. As shown in Figure 2, the HPLC chromatogram of the crude extract shows several compounds where the content of target compounds $\mathbf{1}, 2$ and 3 is 1.6, 8.9, and 10.1\%, respectively, based on the HPLC peak area percentage. 


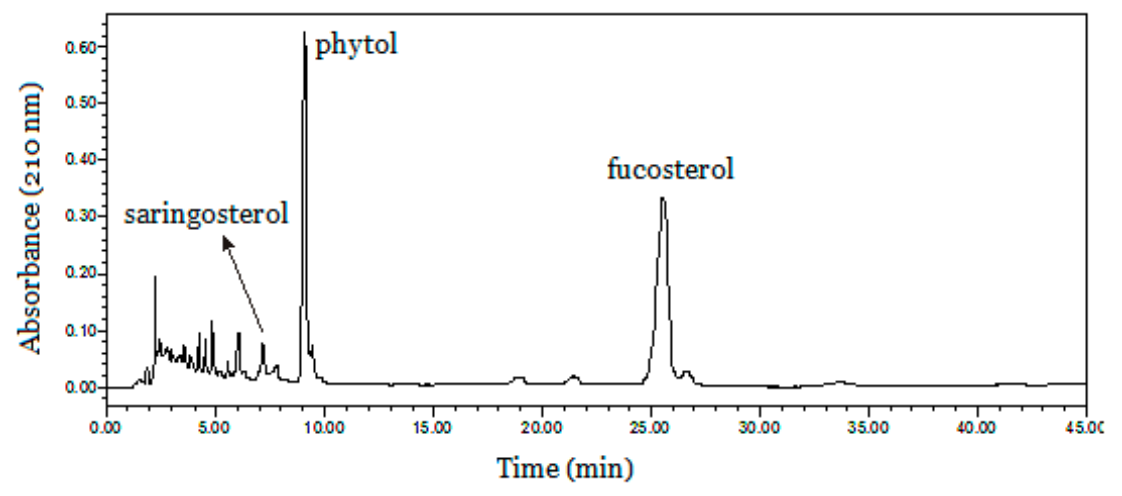

Figure 2. HPLC analysis of the crude S. horneri extract.

\subsection{Selection of Two-phase Solvent System for CCC}

The crude $S$. horneri extracts have lipophilic physical properties and are soluble in non-polar solvent. Therefore, $n$-hexane-acetonitrile solvent system was selected to separate the target compounds due to it satisfying the requirements. To achieve a successful separation using HSCCC, the partition coefficient $(K)$ is the most important parameter for the selection of the solvent system, which should be in the range of 0.5-2.0 to get an efficient separation and a suitable run time. Small $K$ value usually results in poor resolution, while a large $K$ value tends to get a broader peak and more dilute peak fractions due to a longer elution time. In the present study, different kinds of solvent systems were tested. As seen in Table 1, when the solvent system $n$-hexane-acetonitrile $(1: 1, v / v)$ was used, compounds 2 and 3 gave very large $K$ values, implying broader peak and longer separation time, which was not ideal for rapid CCC separation. When $n$-hexane-acetonitrile-dichloromethane $(10: 7: 3, v / v), n$-hexane-acetonitrile-dichloromethane $(8: 7: 3, v / v)$, and $n$-hexane-dichloromethane-methanol-acetonitrile (10:3:2:5, v/v) were used, the targets produced appropriate $K$ values. However, the separation factor should also be taken into consideration. As shown in Table 1, the peak resolution between compound $\mathbf{1}$ and compound $\mathbf{2}$ was extremely fine $(\alpha>1.5)$ for all the studied systems, indicating that the saringosterol was easily separated from phytol. On the contrary, the separation factor between compound 2 and compound 3 was close to 1.0 for these three systems. Therefore, it was almost impossible to achieve baseline separation in a single CCC run. Consequently, according to the literature [22], the biphasic liquid systems composed of $n$-hexane-acetonitrile-methanol at different ratios have been under evaluation. Data shown in Table 1 indicates that this series of biphasic liquid systems can produce appropriate $K$ values for all targets. Moreover, the separation factor of phytol and fucosterol was greatly improved. When the two-phase solvent system composed of $n$-hexane-acetonitrile-methanol $(5: 5: 6, v / v)$ was used, the peak resolution between phytol and fucosterol was better. Therefore, this solvent combination was selected for the subsequent CCC separations.

Table 1. The $K$ values of target compounds in different solvent systems.

\begin{tabular}{|c|c|c|c|c|}
\hline \multirow{2}{*}{ Solvent System $(v / v)$} & \multicolumn{3}{|c|}{$K$ Value } & \multirow{2}{*}{$\begin{array}{l}\text { Separation } \\
{\text { Factor }(\alpha)^{\text {a }}}^{\text {a }}\end{array}$} \\
\hline & Saringosterol (1) & Phytol (2) & Fucosterol (3) & \\
\hline n-hexane-acetonitrile (1:1) & 0.97 & 3.55 & 4.42 & 1.25 \\
\hline$n$-hexane-acetonitrile-dichloromethane (10:7:3) & 0.79 & 2.43 & 2.73 & 1.12 \\
\hline$n$-hexane-acetonitrile-dichloromethane (8:7:3) & 0.68 & 2.37 & 2.51 & 1.06 \\
\hline $\begin{array}{l}n \text {-hexane-dichloromethane-methanol-acetonitrile } \\
(10: 3: 2: 5)\end{array}$ & 0.43 & 1.06 & 1.07 & 1.01 \\
\hline$n$-hexane-acetonitrile-methanol (5:5:3) & 0.94 & 1.78 & 2.32 & 1.30 \\
\hline$n$-hexane-acetonitrile-methanol (5:5:4) & 0.84 & 1.59 & 2.18 & 1.37 \\
\hline$n$-hexane-acetonitrile-methanol (5:5:6) & 0.72 & 1.40 & 2.02 & 1.44 \\
\hline
\end{tabular}

${ }^{a}$ Separation factor of compound 2 and $3\left(\alpha=K_{3} / K_{2}\right)$. 


\subsection{Studies on the Retention of the Stationary Phase}

CCC is a unique liquid-liquid partition chromatography without the use of solid support matrix. Thus, the retention of the stationary phase $\left(S_{\mathrm{F}}\right)$ is a very important parameter in this chromatographic method. The higher the retention of the stationary phase, the better the peak resolution. Generally speaking, the value of $S_{\mathrm{F}}$ is affected by various factors such as the physical properties of the two-phase solvent system, column geometry, revolutional speed of the column, and the flow rate of the mobile phase $[16,17]$. Because of the complex hydrodynamic behavior of the two phases in the column, retention of the stationary phase under a given set of conditions is best determined by actual experimentation.

In the present studies, with a two-phase solvent system composed of $n$-hexane-acetonitrilemethanol $(5: 5: 6, v / v)$, the effects of applied centrifugal-force field and the flow rate of mobile phase on the value of $S_{\mathrm{F}}$ (retention of the stationary phase, \%) were under systematic considerations. The results are summarized in Figure 3, where the percentage retention of the stationary phase was plotted against the applied revolutional speeds (Figure 3A), as well as the mobile phase flow rates (Figure 3B). In general, retention of $50 \%$ is considered to be satisfactory. The retention curves in Figure 3 show that $S_{\mathrm{F}}$-values are almost over $50 \%$ under each experimental condition, indicating that the selected two-phase solvent system is very suitable for a preparative HSCCC method. In addition, both reducing the flow rate and expediting the rotary speed can increase the retention of the stationary phase. Thus, when the revolutional speed was $1000 \mathrm{rpm}$, and the flow rate of the mobile phase was $1.0 \mathrm{~mL} \mathrm{~min}{ }^{-1}$, the value of $S_{\mathrm{F}}$ could get to its maximum. However, longer elution time and broader peaks could be caused by a lower flow rate. In addition, considering the mechanical aspect of the instrument's rotor, the flow rate of the mobile phase was set at $2.0 \mathrm{~mL} \mathrm{~min}^{-1}$, and the rotary speed of the column was performed at $800 \mathrm{rpm}$ during all separations.
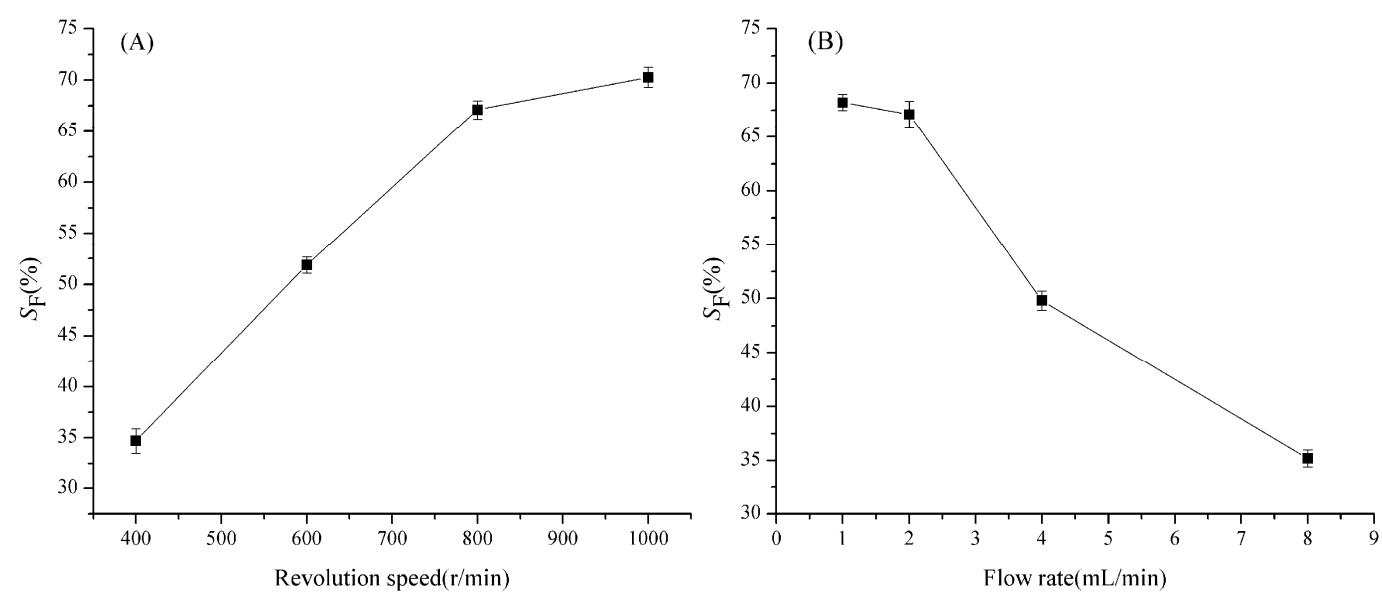

Figure 3. (A) Effect of rotating speed on the stationary phase retention (flow rate: $2.0 \mathrm{~mL} \mathrm{~min}^{-1}$ ).

(B) Effect of flow rate on the stationary phase retention (rotary speed: $800 \mathrm{rmp}$ ).

\subsection{HSCCC Separations}

Figure 4 illustrates the preparative HSCCC separation of target components from $300 \mathrm{mg}$ of crude S. horneri extract with the biphasic solvent system composed of $n$-hexane-acetonitrile-methanol (5:5:6, $v / v)$. The CCC separation was performed on the $140 \mathrm{~mL}$-capacity instrument. In order to keep the satisfactory peak resolution, the flow rate was set at $2.0 \mathrm{~mL} / \mathrm{min}$, and rotary speed was set at $800 \mathrm{rpm}$. After hydrodynamic equilibrium was reached, $10.0 \mathrm{~mL}$ sample solution (samples were dissolved in a 1:1 mixture of upper and lower phase) containing $300 \mathrm{mg}$ crude extract was manually injected into the sample loop. The effluent from the tail end of the separation column was continuously monitored with a UV detector at $210 \mathrm{~nm}$. Under the above optimum conditions, satisfactory stationary phase retention was obtained $\left(S_{\mathrm{F}}=67.1 \%\right)$. In order to save solvents and time, the elution-extrusion separation 
mode [23,24] was employed, and the extrusion process was employed after $180 \mathrm{~min}$ : Two immiscible phases leave the column during the EECCC separation. The shading scheme on the $x$-axis (Figure 4 ) shows the positions of the different elution-extrusion stages: elution and extrusion. A clear jump of the UV signal was observed when the stationary phase replaced the mobile phase in the UV detector. Dramatic noise was also observed. It is presumed that the poor UV detection was mainly due to micro-droplets of the mobile phase (lower phase) staying in the detector cell and perturbing the light beam.

As seen in Figure 4, the entire HSCCC separation process continued for $4 \mathrm{~h}$. Three target fractions could be obtained in $150 \mathrm{~min}$. The eluent corresponding to fractions 1, 2 and $\mathbf{3}$ were collected and evaporated, producing $3.1 \mathrm{mg}$ saringosterol, $19.8 \mathrm{mg}$ phytol, and $23.7 \mathrm{mg}$ fucosterol, respectively, in a single-step separation. Then, the target fractions were analyzed by HPLC (shown in Figure 5A-C) and their purities were both above $85 \%$, as determined by HPLC peak areas (the purity of compounds 1, 2 and 3 were 85.09\%, 96.29\%, and 93.13\%, respectively), which clearly indicate that the two-phase system is very efficient for CCC separation of phytosterols from $S$. horneri.

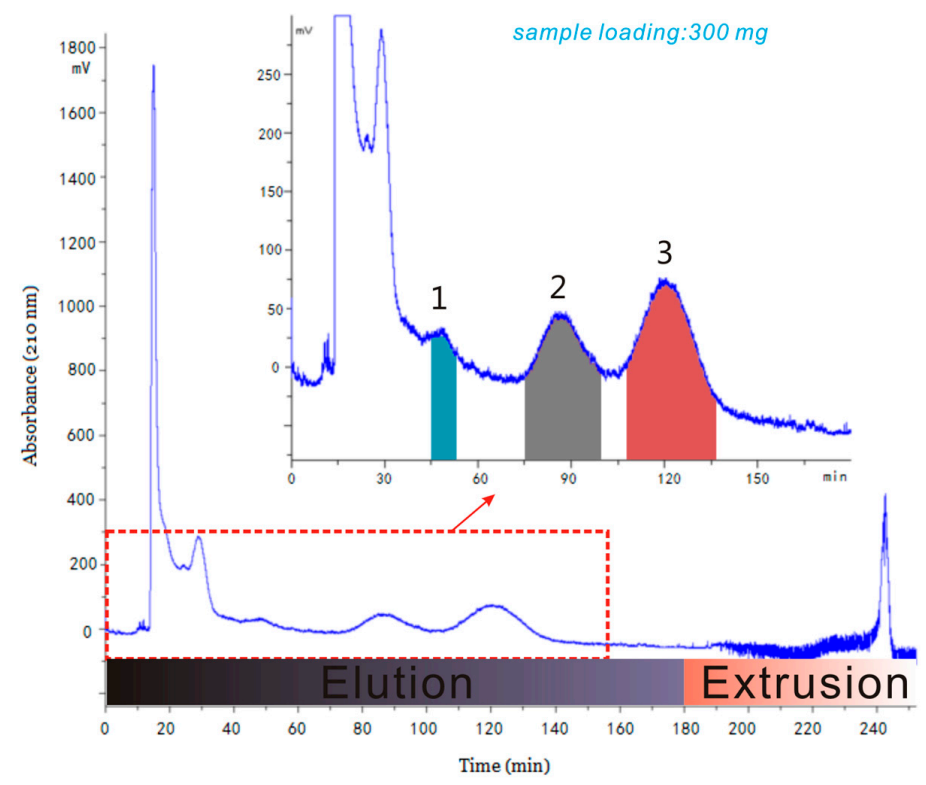

Figure 4. The chromatogram of HSCCC separation of target compounds from S. horneri extracts.

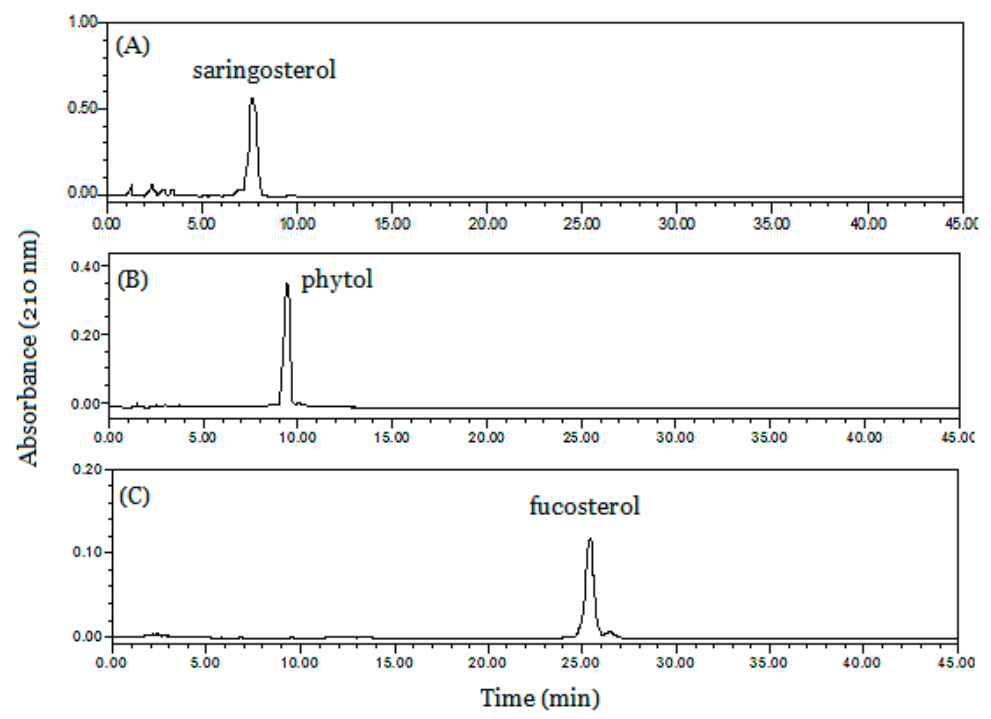

Figure 5. HPLC analysis of obtained HSCCC fractions. (A) CCC fraction 1; (B) CCC fraction 2; (C) CCC fraction 3. 
From the above separation, the advantages of the CCC technique are obvious. First, the use of two-phase solvent systems allows one to choose solvents from an enormous number of possible combinations, making it the most appropriate technique to separate the target compound(s) from a complex sample matrix. Second, it allows sample loads ranging from milligrams to kilograms, depending on the column size. Third, due to the use of biphasic liquid systems, there is no irreversible adsorption caused by a solid support matrix. Thus, the crude $S$. horneri extract can be directly injected for CCC separations with no additional sample pretreatment procedures. This is almost impossible for the preparative HPLC, in which the complex sample matrix always causes contaminations and damage of expensive packing materials, such as reversed-phase silica gel and sephadex gel. In addition, there are practical considerations that make CCC advantageous relative to preparative HPLC. For example, sample solubilization in a biphasic solvent system tends to work very well whereas fairly crude mixtures can be challenging to dissolve in a suitable solvent system for HPLC. Overall, CCC is a promising preparative separation technique, extremely useful for the separation and purification of various natural products.

\subsection{Structure Elucidation of the Isolated Compounds}

The structural identification of compounds 1-3 was performed by ${ }^{1} \mathrm{H}$ and ${ }^{13} \mathrm{C}$ NMR analyses, and the data were compared with literature values. Accordingly, the molecules isolated were identified as saringosterol (1) [14,25,26], phytol (2) [27,28], and fucosterol (3) [14,22,29] (see Supplementary Materials).

\section{Materials and Methods}

\subsection{Reagents and Materials}

Solvents for high-performance liquid chromatography (HPLC) analysis were as follows: acetonitrile and methanol were chromatographic grade and obtained from Merck (Darmstadt, Germany). High-purity water with a resistivity of $18.2 \mathrm{M} \Omega \mathrm{cm}^{-1}$ was obtained from a Milli-Q water system (Millipore, Bedford, MA). Solvents used for CCC and sample preparation were as follows: methanol, acetonitrile, $n$-hexane, and ethanol were analytical grade and purchased from Huadong Chemicals (Hangzhou, China). The NMR solvent was $\mathrm{CDCl}_{3}$ (Fisher Scientific, Loughborough, UK). S. horneri were purchased from Dongtou County, Zhejiang Province. The material was identified by Dr. Juanjuan Chen from School of Marine Sciences, Ningbo University, and a voucher specimen was deposited in our laboratory.

\subsection{Preparation of Crude Extract}

S. horneri were dried to a constant weight in a vacuum oven at $55^{\circ} \mathrm{C}$ and ground into powder for storage in dark conditions. $500 \mathrm{~g}$ of the dried material was extracted with $95 \%$ ethanol (2 L) at $85^{\circ} \mathrm{C}$ for $2.5 \mathrm{~h}$ under reflux. The extraction procedure was repeated three times. The extracts were combined and evaporated to dryness by rotary vaporization at $45^{\circ} \mathrm{C}$, yielding $40 \mathrm{~g}$ of the crude extract, which was stored in a freezer $\left(-20^{\circ} \mathrm{C}\right)$ for the subsequent separation.

In order to removing chlorophylls and lipids, saponification of crude samples was performed according to the method described by Schröder et al. after slight modification [21]. The $30.0 \mathrm{~g}$ of the crude extract was saponated with $100 \mathrm{~mL}$ of $10 \%$ ethanolic potassium hydroxide solution at $65{ }^{\circ} \mathrm{C}$ and stirred for $3 \mathrm{~h}$ under nitrogen atmosphere. Then, the solution was cooled, and $100 \mathrm{~mL} n$-hexane and $100 \mathrm{~mL}$ water were added. The upper phase which contained the unsaponifiable matter was separated. Then the upper organic phase (n-hexane phase) was washed with $30 \%$ aqueous ethanol until the water phase was almost colorless and the $\mathrm{pH}$ was near neutral. After separation, the organic phase was evaporated to dryness by rotary vaporization at $35^{\circ} \mathrm{C}$. The residue $(1.365 \mathrm{~g})$ was stored in a refrigerator $\left(-20^{\circ} \mathrm{C}\right)$ for the subsequent CCC separation. Under this storage condition, the extract and its chemical constitutes are stable for at least half a year. 


\subsection{Determination of Solute Partition Coefficient}

A suitable partition coefficient $(K)$ is usually used as a good sign of the successful CCC separation. The ideal $K$ value is usually considered in the range of 0.5 to 2 [18]. The $K$ value in the solvent system of target compounds in S. horneri was determined by the following method [18]: $2.0 \mathrm{mg}$ crude extract of $S$. horneri was dissolved in $1 \mathrm{~mL}$ of the pre-equilibrated solvent system (upper and lower phases 1:1 $v / v$ ) and sonicated to fully dissolved. After two phases separated, $100 \mu \mathrm{L}$ of each phase was removed and concentrated to dryness. The residue was dissolved in $1 \mathrm{~mL}$ methanol and analyzed by HPLC. The $K$ value was calculated as the ratio of the peak area of the target compound in the upper phase divided by that in the lower phase.

\subsection{Preliminary Studies on Retention of the Stationary Phase}

The percentage of stationary phase volume retained in the rotating coiled column relative to the total column capacity was determined at various revolutional speeds and flow rate. A series of experiments were conducted with the present CCC apparatus with $140 \mathrm{~mL}$ of total capacity in the head-to-tail elution mode. In each series of experiments, the column was first filled with the stationary phase, and then the mobile phase was pumped into the column while it was rotated at a given revolutional speed. After the mobile phase front emerged and hydrodynamic equilibrium state was established in the column, the retention of the stationary phase $\left(S_{\mathrm{F}}\right)$ could be determined by displacing the column contents with a flow of nitrogen. Thus, the $S_{\mathrm{F}}$ was expressed as the ratio of stationary phase retained in the column and the total column capacity.

\subsection{HSCCC Procedures}

CCC separation was accomplished on a type-J CCC instrument [30] manufactured by the Zhejiang University machine shop (Hangzhou, China). The CCC apparatus was designed with one $140 \mathrm{~mL}$ coil and a counterweight. The multilayer coil was prepared by winding a $45 \mathrm{~m} \times 2.0 \mathrm{~mm}$ I.D. PTFE tube for 6 layers. The $\beta$-value $(\beta=r / R$, where $\mathrm{r}$ is the distance from the coil to the holder shaft, and $R$, the revolution radius or the distance between the holder axis and central axis of the centrifuge, $R=8 \mathrm{~cm}$ ) varied from 0.33 at the internal terminal to 0.60 at the external terminal.

In this work, the two-phase solvent system is composed of $n$-hexane-acetonitrile-methanol (5:5:6, $v / v)$. The preparative HSCCC procedures were as follows: the multilayer coiled column was first entirely filled with the upper phase as the stationary phase. The lower phase was then pumped into the head end of the column at a flow rate of $2.0 \mathrm{~mL} / \mathrm{min}$, while the apparatus was rotated at $800 \mathrm{rpm}$. After hydrodynamic equilibrium was reached, $10.0 \mathrm{~mL}$ sample solution (samples were dissolved in a 1:1 mixture of upper and lower phase) containing $300 \mathrm{mg}$ crude extract was injected into the separation column through the injection valve. The effluent from the tail end of the separation column was continuously monitored with a UV detector at $210 \mathrm{~nm}$.

\subsection{HPLC Analysis}

HPLC analysis was performed on a Waters Acquity UPLC system (Waters, Milford, MA, USA), which was equipped with a binary pump, a heated column compartment, an autosampler, a PDA detector, and an Empower workstation. The HPLC separation was achieved on a YMC ODS-A HPLC column (150 mm $\times 4.6 \mathrm{~mm}$ i.d., $5 \mu \mathrm{m}, 120 \AA$ ) protected with an on-line filter. The mobile phase was composed of methanol/acetonitrile $(3: 7, v / v)$ and isocratic elution mode was employed. The column temperature was set at $25^{\circ} \mathrm{C}$. The flow rate was $0.8 \mathrm{~mL} / \mathrm{min}$, and the effluent was monitored at $210 \mathrm{~nm}$.

\subsection{Nuclear Magnetic Resonance Spectroscopy}

${ }^{1} \mathrm{H}$ and ${ }^{13} \mathrm{C}$ Nuclear magnetic resonance spectroscopy (NMR) measurements were performed on a Bruker Advance DMX500 spectrometer (Bruker Biospin, Rheinstetten, Germany) at 500 and $125 \mathrm{MHz}$, 
respectively. Purified compounds were dissolved in $\mathrm{CDCl}_{3}$, and data were processed by WIN-NMR software version 6.1.0.0.

\section{Conclusions}

In conclusion, a high-speed countercurrent chromatographic method was developed and successfully applied to the separation and purification of phytosterols from the crude sample of S. horneri using n-hexane-acetonitrile-methanol $(5: 5: 6, v / v)$ as the two-phase solvent system. Under the optimum conditions, phytol and two analogue sterols were baseline separated, producing $19.8 \mathrm{mg}$ phytol, $23.7 \mathrm{mg}$ fucosterol and $3.1 \mathrm{mg}$ saringosterol from $300 \mathrm{mg}$ of $S$. horneri extract. Our research demonstrates that HSCCC is a suitable and effective protocol for the preparative separation of sterol analogues from the crude $S$. horneri extract.

Supplementary Materials: The following are available online at http:/www.mdpi.com/1660-3397/17/12/691/s1, Figure S1: ${ }^{1} \mathrm{H}$ NMR spectrum of saringosterol (1) $\left(\mathrm{CDCl}_{3}, 500 \mathrm{MHz}\right)$, Figure S2: ${ }^{13} \mathrm{C}$ NMR spectrum of saringosterol $\left(\mathrm{CDCl}_{3}, 125 \mathrm{MHz}\right)$, Figure S3: ${ }^{1} \mathrm{H}$ NMR spectrum of phytol (2) $\left(\mathrm{CDCl}_{3}, 500 \mathrm{MHz}\right)$, Figure S4: ${ }^{13} \mathrm{C}$ NMR spectrum of phytol $\left(\mathrm{CDCl}_{3}, 125 \mathrm{MHz}\right)$, Figure S5: ${ }^{1} \mathrm{H}$ NMR spectrum of fucosterol (3) $\left(\mathrm{CDCl}_{3}, 500 \mathrm{MHz}\right)$, Figure S6: ${ }^{13} \mathrm{C} \mathrm{NMR}$ spectrum of fucosterol ( $\mathrm{CDCl}_{3}, 125 \mathrm{MHz}$ ), Table S1: NMR data of isolated compounds in $\mathrm{CDCl}_{3}$.

Author Contributions: L.G. and Y.L. conceived and designed the experiments; M.X. and C.L. performed the experiments; M.X., C.L., L.G. and Y.L., analyzed the data; M.X. and C.L. wrote the paper; L.G. and Y.L. reviewed and edited the paper.

Funding: This research was funded by Department of Science and Technology of Zhejiang Province (No.LGN18C200015).

Acknowledgments: The authors thank Yaqin Liu from Department of Chemistry, Zhejiang University for her technical support of NMR experiments.

Conflicts of Interest: The authors declare no conflict of interest.

\section{References}

1. Zhang, S.Y.; Wang, L.; Wang, W.D. Algal communities at Gouqi Island in the Zhoushan archipelago, China. J. Appl. Phycol. 2008, 20, 853-861. [CrossRef]

2. Pang, S.J.; Liu, F.; Shan, T.F.; Gao, S.Q.; Zhang, Z.H. Cultivation of the brown alga Sargassum horneri: Reproduction and seedling production in tank culture under reduced solar irradiance in ambient temperature. J. Appl. Phycol. 2009, 21, 413-422. [CrossRef]

3. Yoshioka, H.; Kamata, A.; Konishi, T.; Takahashi, J.; Oda, H.; Tamai, T.; Toyohara, H.; Sugahara, T. Inhibitory effect of chlorophyll c2 from brown algae, Sargassum horneri, on degranulation of RBL-2H3 cells. J. Funct. Foods 2013, 5, 204-210. [CrossRef]

4. Yoshioka, H.; Ishida, M.; Nishi, K.; Oda, H.; Toyohara, H.; Sugahara, T. Studies on anti-allergic activity of Sargassum horneri extract. J. Funct. Foods 2014, 10, 154-160. [CrossRef]

5. Cho, J.Y. Antifouling chromanols isolated from brown alga Sargassum horneri. J. Appl. Phycol. 2013, 25, 299-309. [CrossRef]

6. Ma, A.C.; Chen, Z.; Wang, T.; Song, N.; Yan, Q.; Fang, Y.C.; Guan, H.S.; Liu, H.B. Isolation of the molecular species of monogalactosyl diacyl glycerols from brown edible seaweed Sargassum horneri and their inhibitory effects on triglyceride accumulation in 3T3-L1 adipocytes. J. Agric. Food. Chem. 2014, 62, 11157-11162. [CrossRef]

7. Wena, Z.S.; Xiang, X.W.; Jin, H.X.; Guo, X.Y.; Liu, L.J.; Huang, Y.N.; OuYang, X.K.; Qu, Y.L. Composition and anti-inflammatory effect of polysaccharides from Sargassum horneri in RAW264.7 macrophages. Int. J. Biol. Macromol. 2016, 88, 403-413. [CrossRef]

8. Kim, M.E.; Jung, Y.C.; Jung, I.; Lee, H.W.; Youn, H.Y.; Lee, J.S. Anti-inflammatory effects of ethanolic extract from Sargassum horneri (Turner) C. Agardh on lipopolysaccharide stimulated macrophage activation via NF-KB pathway regulation. Immunol. Invest. 2015, 44, 137-146. [CrossRef] 
9. Chen, Z.; Liu, J.; Fu, Z.F.; Ye, C.; Zhang, R.S.; Song, Y.Y.; Zhang, Y.; Li, H.H.; Ying, H.; Liu, H.B. 24(S)-Saringosterol from edible marine seaweed Sargassum fusiforme is a novel selective LXR $\beta$ agonist. J. Agric. Food Chem. 2014, 62, 6130-6137. [CrossRef]

10. CalPe-Berdiel, L.; Escolà-Gil, J.C.; Rotllan, N.; Blanco-Vaca, F. Phytosterols do not change susceptibility to obesity insulin resistance, and diabetes induced by a high-fat diet in mice. Metabolism 2008, 57, 1497-1501. [CrossRef]

11. Rozner, S.; Verkhovski, L.; Nissimov, Y.; Aserin, A.; Vilensky, R.; Danino, D.; Zouboulis, C.C.; Milner, Y.; Garti, N. Inhibition of cholesterol transport into skin cells in cultures by phytosterol-loaded microemulsion. Chem. Phys. Lipids 2008, 153, 109-118. [CrossRef] [PubMed]

12. Malaviya, A.; Gomes, J. Androstenedione production by biotransformation of phytosterols. Bioresour. Technol. 2008, 99, 6725-6737. [CrossRef] [PubMed]

13. Volger, O.L.; van der Boom, H.; de Wit, E.C.; van Duyvenvoorde, W.; Hornstra, G.; Plat, J.; Havekes, L.M.; Mensink, R.P.; Princen, H.M. Dietary plant stanol esters reduce VLDL cholesterol secretion and bile saturation inapolipoprotein E³-Leiden transgenic mice. Arterioscl. Thromb. Vasc. Biol. 2001, 21, 1046-1052. [CrossRef] [PubMed]

14. Rahelivao, M.P.; Gruner, M.; Andriamanantoanina, H.; Bauer, I.; Knölker, H.J. Brown algae (Phaeophyceae) from the coast of madagascar: Preliminary bioactivity studies and isolation of natural products. Natur. Prod. Bioprosp. 2015, 5, 223-235. [CrossRef]

15. Ito, Y.; Bowman, R.L. Countercurrent chromatography: Liquid-liquid partition chromatography without solid support. Science 1970, 167, 281-283. [CrossRef]

16. Ito, Y. Chapter 1, Principles, Apparatus and Methodology. In High-Speed Countercurrent Chromatography, Chemical Analysis Serials; Ito, Y., Conway, W.D., Eds.; Wiley: New York, NY, USA, 1996; Volume 132, pp. 3-44.

17. Berthod, A. Chapter 1, Fundamentals. In Countercurrent Chromatography, the Support Free Liquid Stationary Phase, Comprehensive Analytical Chemistry; Berthod, A., Ed.; Elsevier: Amsterdam, The Netherlands, 2002; Volume 38, pp. 1-20.

18. Ito, Y. Golden rules and pitfalls in selecting optimum conditions for high-speed counter-current chromatography. J. Chromatogr. A 2005, 1065, 145-168. [CrossRef]

19. Wood, P.; Ignatova, S.; Janaway, L.; Keay, D.; Hawes, D.; Garrard, I.; Sutherland, I.A. Counter-current chromatography separation scaled up from an analytical column to a production column. J. Chromatogr. A 2007, 1151, 25-30. [CrossRef]

20. Schröder, M.; Vetter, W. High-speed counter-current chromatographic separation of phytosterols. Anal. Bioanal. Chem. 2011, 400, 3615-3623. [CrossRef]

21. Schröder, M.; Vetter, W. Investigation of unsaponifiable matter of plant oils and isolation of eight phytosterols by means of high-speed counter-current chromatography. J. Chromatogr. A 2012, 1237, 96-105. [CrossRef]

22. Xiao, X.H.; Yuan, Z.Q.; Li, G.K. Preparation of phytosterols and phytol from edible marine algae by microwave-assisted extraction and high-speed counter-current chromatography. Sep. Purif. Technol. 2013, 104, 284-289. [CrossRef]

23. Berthod, A.; Ruiz-Angel, M.J.; Carda-Broch, S. Elution-extrusion countercurrent chromatography. Use of the liquid nature of the stationary phase to extend the hydrophobicity window. Anal. Chem. 2003, 75, 5886-5894. [CrossRef]

24. Berthod, A.; Friesen, J.B.; Inui, T.; Pauli, G.F. Elution-extrusion countercurrent chromatography theory and concepts in metabolic analysis. Anal. Chem. 2007, 79, 3371-3382. [CrossRef]

25. Guyot, M.; Davoust, D.; Belaud, C. Hydroperoxy-24-vinyl-24-cholésterol, nouvel hydroperoxide naturel isolé de deux tuniciers: Phallusia mamillata et ciona intestinalis. Tetrahedron Lett. 1982, 23, 1905-1906. [CrossRef]

26. Shi, D.Y.; Fan, X.; Sun, J.; Han, L.J.; Shi, J.G. Steroids from green alga Chaetomorpha basiretorsa Setchell. Chin. J. Oceanol. Limn. 2008, 26, 415-418. [CrossRef]

27. Su, H.; Zhu, X.B.; Yuan, Z.H.; Li, J.; Guo, S.J.; Han, L.J.; Shi, D.Y. Studies on the chemical constituents of Domatopsis cartilaginosa. Chin. J. Mar. Sci. 2009, 33, 33-35. (In Chinese)

28. Brown, G.D.; Liang, G.Y.; Sy, L.K. Terpenoids from the seeds of Artemisia annua. Phytochemistry 2003, 64, 303-323. [CrossRef] 
29. Lee, S.; Lee, Y.S.; Jung, S.H.; Kang, S.S.; Shin, K.H. Anti-oxidant activities of fucosterol from the marine algae Pelvetia siliquosa. Phytochemistry 2003, 26, 719-722.

30. Ito, Y. Efficient preparative counter-current chromatography with a coil planet centrifuge. J. Chromatogr. A 1981, 214, 122-125. [CrossRef]

(C) 2019 by the authors. Licensee MDPI, Basel, Switzerland. This article is an open access article distributed under the terms and conditions of the Creative Commons Attribution (CC BY) license (http://creativecommons.org/licenses/by/4.0/). 